\title{
Assessment of IL-10 Polymorphism and TGF beta 1 Polymorphism in Egyptian Patients with Chronic Liver Disease
}

\author{
Magda H. Osman ${ }^{1}$, Radwa S. Shahin ${ }^{1}$, Wafaa M. Elzefzafy ${ }^{2}$, Maha R.Ghazzawi ${ }^{1}$ \\ ${ }^{1}$ Department of Clinical and Chemical Pathology, ${ }^{2}$ Department of Tropical Medicine, Faculty of Medicine (for Girls), \\ Al-Azhar University
}

Corresponding author: Maha R. Ghazzawi; Mobile: 01122996448; Email: mahaghazzawi@ hotmail.com

\begin{abstract}
Aim of the work: to determine the role of Interleukin-10 (IL-10) polymorphism (rs 1800896) and Transforming Growth Factor-Beta-1(TGF- $\beta 1$ ) polymorphism (509 CT) as markers for cirrhosis in Egyptian patients with chronic liver disease. Subjects and Methods: This case-control study was carried out on selected patients admitted to Tropical medicine department, Al Zahraa University Hospital during the period from March 2016 to April 2017. Genotyping of IL-10 (rs 1800896) and TGF- $\beta 1$ (509 CT) polymorphisms were performed using real-time polymerase chain reaction (PCR) technique. Results: There was significant increase in IL10 and TGF $\beta 1509$ gene polymorphisms in compensated and de-compensated groups as compared to control group. Conclusion: Interleukin 10 rs 1800896 gene polymorphism and TGF $\beta 1509$ gene polymorphism are associated with risk of liver cirrhosis in patients with chronic hepatitis $\mathrm{C}$ virus infection. These findings could be useful for future screening for early detection of liver cirrhosis.
\end{abstract}

Key words: IL-10, polymorphism, TGF Beta, chronic liver disease

\section{INTRODUCTION}

Chronic liver disease (CLD) and its end stages, cirrhosis and hepatocellular carcinoma (HCC), are leading causes of morbidity and mortality worldwide with numerous socioeconomic costs. Patients with liver cirrhosis are at high risk of deadly hepatic failure and well over $80 \%$ of HCC develop on a cirrhotic background ${ }^{(1)}$.

Chronic liver diseases (CLDs) are defined as the continuity of clinical and biochemical evidence of hepatic dysfunction for longer than six months. Hepatitis $\mathrm{B}$ and $\mathrm{C}(\mathrm{HBV}, \mathrm{HCV})$ are, and will remain for some time, major health problems in Egypt. Both infections can lead to an acute or silent course of liver disease ${ }^{(\mathbf{1})}$.

Hepatic fibrosis, which represents the wound healing response of the liver, is a common sequel of liver injury characterized by excess deposition and altered composition of extra-cellular matrix (ECM) ${ }^{(2)}$.

Cirrhosis means scar tissue in the liver which restricts the flow of blood and leads to portal hypertension, resulting in complications such as ascites, spontaneous bacterial peritonitis, esophageal varices and other potentially life-threatening complications ${ }^{(2)}$.

Compensated cirrhosis means that the liver is heavily scarred, but can still perform many important bodily functions. Many people with compensated cirrhosis experience few or no symptoms and can live for many years without serious complications, where de-compensated cirrhosis indicates that the liver is extensively scarred and unable to function properly. People with de-compensated cirrhosis eventually develop many symptoms and complications that can be life threatening ${ }^{(2)}$.
Liver cell failure is the end stage of cirrhosis and is presented by hepatic encephalopathy (HE). Signs include hepatic fetor, asterixis, mental confusion, stupor and coma ${ }^{(3)}$.

Up till now, liver biopsy is essential in establishing the diagnosis of liver fibrosis. Beside invasiveness, liver biopsy has many complications like sampling error and $\operatorname{cost}{ }^{(3)}$.

This situation strengthens the need for harmless, alternative and complementary non invasive serum biomarkers, that are safe, inexpensive and reliable ${ }^{(3)}$.

Interleukin 10 (IL-10) is a potent antiinflammatory cytokine that plays a crucial, and often essential, role in preventing inflammatory and autoimmune pathologies ${ }^{(4)}$.

Serum IL-10 concentration has been reported to be significantly elevated in patients with chronic HCV and IL-10 may be related to hepatocarcinogenesis with suppression of immune surveillance ${ }^{(5)}$.

In consistence with Othman et al. (9) $\mathrm{IL}-10$ concentration was elevated in patients with $\mathrm{HCV}$, cirrhosis, and HCC and the concentrations are associated with disease progression indicating that IL-10 reflects the degree of inflammation in the liver and may be related to the development of HCC. However, increased circulating IL10 has been reported in patients with different types of tumors including resectable $\mathrm{HCC}^{(6)}$.

These results may be explained on the basis that the high serum IL-10 levels in patients with HCC result from the secretion of IL-10 by tumor cells, in addition to the production at the site of inflammatory changes with activated infiltrating mononuclear cells in the liver ${ }^{(7)}$. 
Transforming Growth Factor $\beta 1$ is a central regulator in chronic liver disease contributing to all stages of disease progression from initial liver injury through inflammation and fibrosis to cirrhosis and HCC. The role of TGF- $\beta 1$ in modulating liver fibrosis progression has been extensively investigated. This cytokine favours the transition of hepatic stellate cells to myofibroblastlike cells, stimulates the synthesis of extracellular matrix proteins and inhibits their degradation ${ }^{(8)}$.

In the liver, hepatic stellate cells (HCS) are considered as the major fibrotic precursor cells that transdifferentiate to fibrogenic, extracellular matrix producing myofibroblasts in inflammatory liver tissue upon TGF- $\beta$ signaling, whereas hepatocytes undergo apoptosis upon signaling by this cytokine ${ }^{(2)}$.

One of the mechanisms whereby cells undergo neoplastic transformation and escape from normal growth control involves an altered response to the cytostatic effects of TGF- $\beta{ }^{(8)}$.

\section{AIM OF THE WORK}

Is to determine the role of IL-10 polymorphism (rs 1800896) \& TGF betalpolymorphism (509 CT) as markers for cirrhosis in Egyptian patients with chronic liver disease.

\section{SUBJECTS AND METHODS}

\section{SUBJECTS}

The present study was a case-control study, performed on selected patients admitted to Tropical medicine department, Al Zahraa University Hospital during the period from March 2016 to April 2017. An oral consent was taken from patients and healthy volunteers after explaining the purpose of the study. The study was approved by the Ethics Board of Al-Azhar University.

This study was carried out on 60 subjects.They were divided into three groups: Patients group (A):20 compensated chronic liver disease patients. Patients group (B):20 decompensated chronic liver disease patients. Control group: 20 completely healthy individuals ofcompatible age and sex. Criteria for diagnosis of chronic liver disease were based on clinical evaluation, biochemical parameters and ultra sound examination.

All patients were subjected to the following: 1- Full history and clinical examination with stress on manifestations of liver cell faileur. 2-
Abdominal ultra-sonography and CT scan for suspected cases of malignancy.

Patients and controls were subjected to the laboratory tests.

Blood samples were taken from patients and control subjects. Each blood sample was divided into three portions as follows: First portion was collected into $\mathrm{Na}$ citrate -containing tube, and used for estimation of prothrombin time (PT) immediately. The second portion was collected into EDTA containing tube for DNA extraction and CBC estimation using fully automated cell counter (Sysmex, USA). The third portion was put in a plain tube, left to clot then centrifuged at $1600 \mathrm{rpm}$ for 20minutes and serum was separated and used for estimation of: Liver and kidney function tests were done on Hitachi 911auto-analyzer (U.SA.). Alfa-feto protein was measured by chemiluminescent immunoassay (Immulite 1000 Chemiluminescent Immunometric Assay, Diagnostic Products Corporation,Siemens, USA). $\mathrm{Hbs} \mathrm{Ag}$ and HCVab using ELISA technique.

Genotyping of IL-10 (rs 1800896) andTGF betal (509 CT) single neucleotide polymorphisms (SNP): The IL-10 (rs 1800896) and TGF- $\beta 1$ (509 CT) SNP polymorphisms were selected. Genotyping was conducted using the real-time polymerase chain reaction (PCR). Real time PCR amplification was done by RotorGene Q Real Time PCR instruments from Qiagen USA, Using real-time PCR kit (Lot Number 4351379 Rev. E Applied Bio-systems 03/2017). Total genomic DNA was extracted from peripheral venous blood of each individual using fully automated QIAcube and QIAamp DNA Blood Mini Kit Qiagen, Germany.The amount of DNA was measured spectrophotometrically using the Nanodrop ND1000 spectrophotometer (Germany) for concentration and purity. All samples at optical density (OD) $260 / 280 \mathrm{~nm}$ had ratio $>1.8$, indicating high purity.The SNP Genotyping Assay contains sequence-specific forward and reverse primers to amplify the polymorphic sequence of interest. The following primer pairs were used: Two TaqMan® ${ }^{\circledR}$ MGB probes: One probe labeled with VIC® dye detects the Allele 1 sequence. One probe labeled with FAM ${ }^{\mathrm{TM}}$ dye detects the Allele 2 Sequence. Sequence of used probes in detection of IL- 10 SNPs rs 1800896: 5'CTACTAAGGCTTTTTGGGAG-3' (forward) and 5'ACTACTAAGGCTTCTTTGGGAA-3' (reverse). Sequence of used probes in detection of TGF- $\beta 1$ SNPs: RS 1800469 using forward primer: 5'GGAGAGCAATTCTTACAGGTG $-3^{\prime}$ and reverse primer: 5'-TAGGAGAAGGAGGGTCTGTC -3'. Target DNA sequences were amplified in a total volume of $20 \mu \mathrm{L}$, 
containing $10 \mu \mathrm{L}$ Taq Man Universal PCR Master Mix.Thermal cycling conditions were $10 \mathrm{~min}$ at $95^{\circ} \mathrm{C}$ followed by 50 cycles of $15 \mathrm{sec}$ at $92^{\circ} \mathrm{C}$ (denature) and 90 $\mathrm{sec}$ at $60^{\circ} \mathrm{C}$ (anneal/extend).The fluorescence products were differentiated by ABI sequencer 377 (Applied Biosystems).

\section{Statistical Analysis}

Data were collected, revised, coded and entered to the Statistical Package for Social Science (IBM SPSS) version 23. The quantitative data were presented as mean, standard deviations and ranges when their distribution found parametric while data with non parametric distribution were presented as median with interquartile range. Also qualitative variables were presented as number and percentages.

The comparison between groups with qualitative data were done by using Chi-square test and Fisher exact test instead of the Chi-square only when the expected count in any cell found less than 5 .

The comparison between more than two independent groups with quantitative data and parametric distribution was done by using One Way Analysis of Variance (ANOVA) followed by post hoc analysis using LSD test.

The comparison between more than two independent groups with quantitative data and nonparametric distribution was done by using Kruskall-Wallis test followed by post hoc analysis using Mann-Whitney test.

The confidence interval was set to $95 \%$ and the margin of error accepted was set to $5 \%$. So, the p-value was considered significant as the following: $P>0.05$ : Non significant. $\mathrm{P}<0.05$ : Significant. $\mathrm{P}<0.01$ : Highly significant.

\section{RESULTS}

The results and data were collected and analyzed in tables 1-7 and figures 1-7.

Certain clinical data were present in the decompensated group (table 1).

The ultra-sonogrphic finding show high significant difference in dilated portal vein and size of the left lobe of the liver in de-compensated group in comparison to control group (table 2).

The liver function tests show highly significant increase in AST, ALT billirubin level, P.T., and INR level and highly significant decrease in albumin and prothrombin concentration in de-compensated in comparison to control group (table 3).

The $\alpha$-feto protein level show highly significant increase in de-compensated group in comparison to control group (table 4).

Table (5) show significant difference in IL10 polymorphism in comparing de-compensated group versus control group regarding homozygous mutant type AA and heterozygous mutant type GA.

Transforming growth factor $\beta 1$ polymorphism show significant difference in comparing compensated versus control group regarding homozygous mutant type $\mathrm{CC}$ and wild type TT (table 6).

Table (1): Comparison of the clinical data among the studied groups.

\begin{tabular}{|l|c|c|c|c|c|c|}
\hline \multirow{2}{*}{} & \multicolumn{2}{|c|}{ Compensated } & \multicolumn{2}{|c|}{ Decompensated } & test value* & P-value \\
\cline { 2 - 7 } & No. & $\%$ & No. & $\%$ & & \\
\hline Fever & 1 & $5 \%$ & 12 & $60 \%$ & 20.114 & $0.0 \mathrm{HS}$ \\
\hline Abd pain & 6 & $30 \%$ & 17 & $85 \%$ & 23.571 & $0.001 \mathrm{HS}$ \\
\hline Loss of wt & 4 & $20 \%$ & 14 & $70 \%$ & 18.143 & $0.001 \mathrm{HS}$ \\
\hline Easy fatigability & 7 & $35 \%$ & 18 & $90 \%$ & 25.038 & $0.000 \mathrm{HS}$ \\
\hline Nausea & 5 & $25 \%$ & 17 & $85 \%$ & 24.432 & $0.000 \mathrm{HS}$ \\
\hline Vomiting & 3 & $15 \%$ & 14 & $70 \%$ & 19.920 & $0.0 \mathrm{HS}$ \\
\hline Jaundice & 5 & $25 \%$ & 16 & $80 \%$ & 25.290 & $0.0 \mathrm{HS}$ \\
\hline Haematemsis & 2 & $10 \%$ & 13 & $65 \%$ & 19.967 & $0.001 \mathrm{HS}$ \\
\hline Melena & 2 & $10 \%$ & 13 & $65 \%$ & 19.857 & $0.001 \mathrm{HS}$ \\
\hline L.L.oedema & 2 & $10 \%$ & 18 & $90 \%$ & 35.667 & $0.0 \mathrm{HS}$ \\
\hline
\end{tabular}

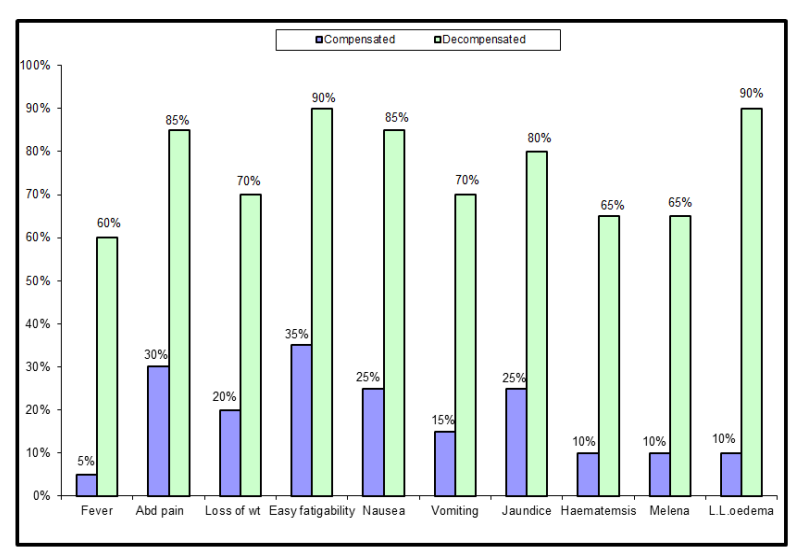

Fig (1): The clinical data among the studied groups.

Table (2): Comparison of ultra sonographic finding among the studied groups.

\begin{tabular}{|c|c|c|c|c|c|c|c|c|c|}
\hline & & \begin{tabular}{|c|} 
Compensated \\
No. $=20$
\end{tabular} & \begin{tabular}{|c|} 
Decompensated \\
No. $=20$
\end{tabular} & \begin{tabular}{|c|} 
Control \\
No. $=20$ \\
\end{tabular} & Test value & P-value & P1 & P2 & P3 \\
\hline Rt lobe & $\begin{array}{l}\text { Mean } \\
\pm \mathrm{SD}\end{array}$ & $14.44 \pm 1.48$ & $13.34 \pm 1.34$ & $13.80 \pm 1.03$ & 3.232 • & 0.049 & $0.015 \mathrm{~s}$ & $0.229 \mathrm{NS}$ & $0.380 \mathrm{NS}$ \\
\hline Lt lobe & $\begin{array}{l}\text { Mean } \\
\pm \mathrm{SD} \\
\end{array}$ & $9.73 \pm 1.75$ & $8.89 \pm 1.92$ & $11.00 \pm 1.15$ & $2.759 \cdot$ & 0.074 & $0.269 \mathrm{NS}$ & $0.176 \mathrm{NS}$ & $0.024 \mathrm{~S}$ \\
\hline Spleen & \begin{tabular}{|l|} 
Mean \\
$\pm \mathrm{SD}$ \\
\end{tabular} & $13.72 \pm 1.91$ & $14.30 \pm 1.94$ & $12.70 \pm 0.42$ & 2.577 . & 0.087 & $0.334 \mathrm{NS}$ & $0.162 \mathrm{NS}$ & $0.028 \mathrm{NS}$ \\
\hline P.V. (mm) & $\begin{array}{l}\text { Mean } \\
\pm \mathrm{SD}\end{array}$ & $11.01 \pm 1.83$ & $11.66 \pm 1.87$ & $9.30 \pm 1.06$ & $5.199 \bullet$ & 0.009 & $0.3 \mathrm{NS}$ & $0.027 \mathrm{~S}$ & $0.002 \mathrm{HS}$ \\
\hline \multicolumn{2}{|c|}{ Ascites* } & $1(5 \%)$ & $17(85 \%)$ & $0(0 \%)$ & $X=35.531$ & $0.000 \mathrm{HS}$ & \begin{tabular}{l|l}
$\mathrm{S}$ & $0.0 \mathrm{HS}$ \\
\end{tabular} & $0.472 \mathrm{~N}$ & $\mathrm{~S} 0.001 \mathrm{HS}$ \\
\hline
\end{tabular}




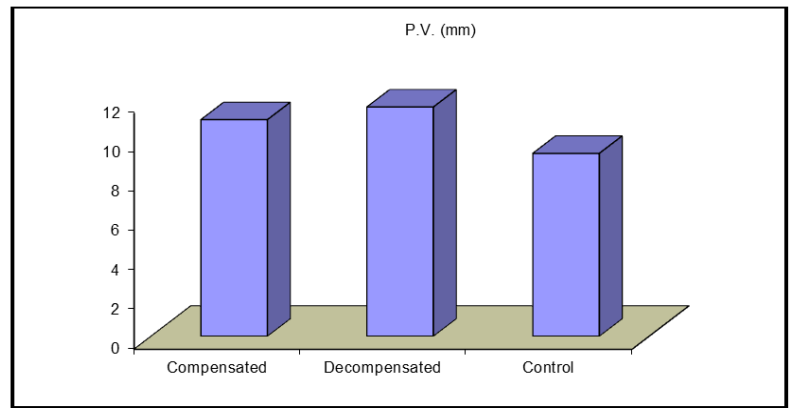

Fig (2): Portal vein diameter in the studied groups.

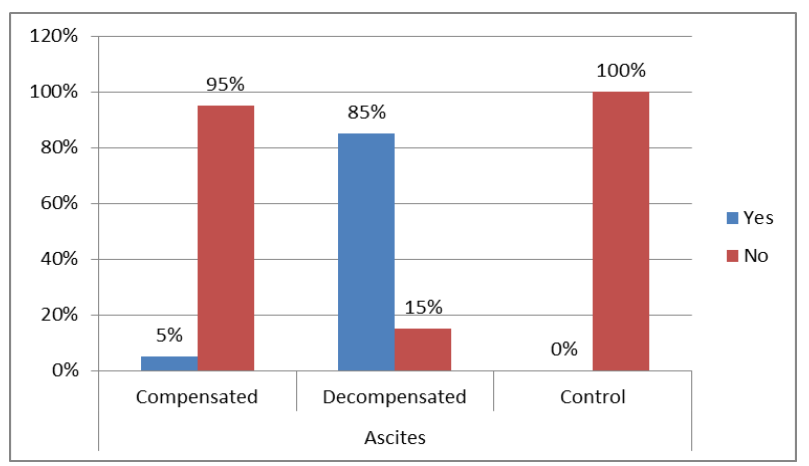

Fig (3): Ascites in the studied groups.

Table (3): Comparison of the liver function tests among the studied groups.

\begin{tabular}{|c|c|c|c|c|c|c|c|c|c|}
\hline & Compensated & Decompensated & Control & \multirow{2}{*}{ test value } & \multirow{2}{*}{ P-value } & \multirow{2}{*}{ P1 } & \multirow{2}{*}{ P2 } & \multirow{2}{*}{ P3 } \\
\hline & & No. $=20$ & No. $=20$ & No. $=20$ & & & & & \\
\hline $\begin{array}{l}\text { Fasting } \\
\text { Blood sugar }\end{array}$ & Mean \pm SD & $111.95 \pm 1.85$ & $96.95 \pm 1.51$ & $92.80 \pm 1.41$ & 0.811 & 0.451 & $0.301 \mathrm{NS}$ & $0.281 \mathrm{NS}$ & 0.81 \\
\hline ALT (U/L) & Mean \pm SD & $36.20 \pm 1.73$ & $45.85 \pm 1.50$ & $24.30 \pm 1.58$ & 1.928 & $0.157 \mathrm{NS}$ & $0.293 \mathrm{NS}$ & $0.289 \mathrm{NS}$ & $0.001 \mathrm{HS}$ \\
\hline AST (U/L) & Mean \pm SD & $35.60 \pm 1.51$ & $69.10 \pm 35.97$ & $23.50 \pm 1.40$ & 9.353 & $0.001 \mathrm{HS}$ & $0.011 \mathrm{HS}$ & $0.317 \mathrm{NS}$ & $0.001 \mathrm{HS}$ \\
\hline Albumin (g/dl) & Mean \pm SD & $3.75 \pm 0.65$ & $2.32 \pm 1.07$ & $4.56 \pm 0.46$ & 27.198 & $0.001 \mathrm{HS}$ & $0.01 \mathrm{HS}$ & $0.019 \mathrm{~S}$ & $0.001 \mathrm{HS}$ \\
\hline Bilirubin (mg/dl) & Mean \pm SD & $1.09 \pm 0.29$ & $3.19 \pm 0.37$ & $0.86 \pm 0.14$ & 19.429 & $0.001 \mathrm{HS}$ & $0.01 \mathrm{HS}$ & 0.287 & $0.001 \mathrm{HS}$ \\
\hline $\begin{array}{l}\text { Prothrombin } \\
\text { concentration \% }\end{array}$ & Mean \pm SD & $92.90 \pm 1.82$ & $60.79 \pm 1.59$ & $95.30 \pm 4.03$ & 31.152 & $0.001 \mathrm{HS}$ & $0.001 \mathrm{HS}$ & $0.670 \mathrm{NS}$ & $0.001 \mathrm{HS}$ \\
\hline INR & Mean \pm SD & $1.05 \pm 0.16$ & $1.48 \pm 0.24$ & $0.85 \pm 0.12$ & 44.337 & $0.001 \mathrm{HS}$ & $0.001 \mathrm{HS}$ & $0.008 \mathrm{HS}$ & $0.001 \mathrm{HS}$ \\
\hline
\end{tabular}

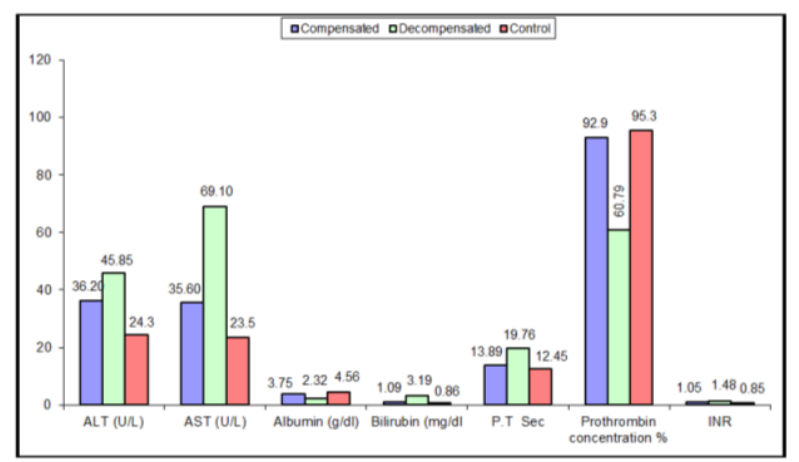

Fig (4): Liver function tests among the studied groups.
Table (4): Comparison of $\alpha$ feto protein results among the studied groups.

\begin{tabular}{|c|c|c|c|c|c|c|c|c|}
\hline $\begin{array}{c}\text { Alpha } \\
\text { FP(IU/ml) }\end{array}$ & \begin{tabular}{|c} 
Compensated \\
No. $=20$ \\
\end{tabular} & $\begin{array}{c}\text { Decompensated } \\
\text { No. }=\mathbf{2 0}\end{array}$ & \begin{tabular}{|c|} 
Control \\
No. $=\mathbf{2 0}$ \\
\end{tabular} & test value & P-value & P1 & P2 & P3 \\
\hline $\begin{array}{c}\text { Median } \\
\text { (IQR) }\end{array}$ & $2(1.4-2.45)$ & $3(2-4.72)$ & & 8.753 & $0.013 \mathrm{HS}$ & & $150 \mathrm{~N}$ & 008HS \\
\hline Range & $1-4.27$ & $0.8-300$ & $0.5-2.5$ & & & & & \\
\hline
\end{tabular}

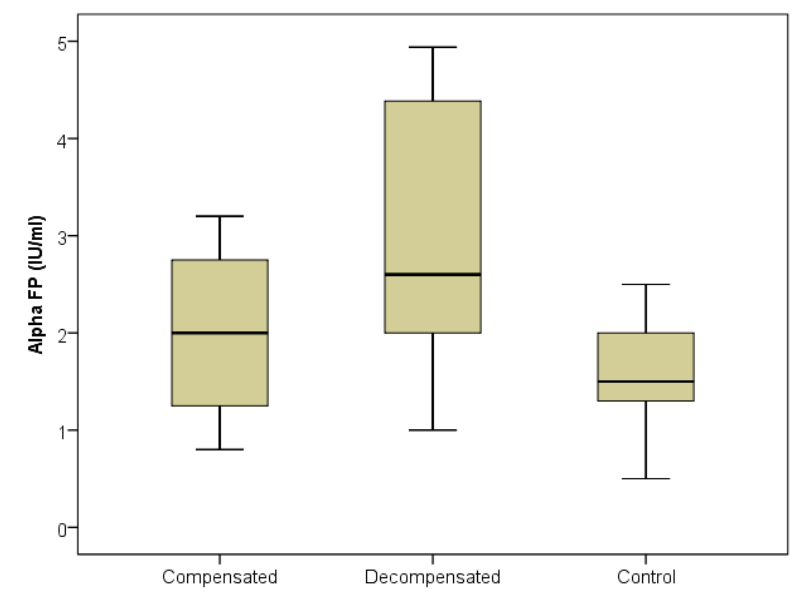

Fig. (5): $\alpha$-feto protein of the studied groups.

Table (5): Comparison of IL 10 polymorphism different allels among the studied groups.
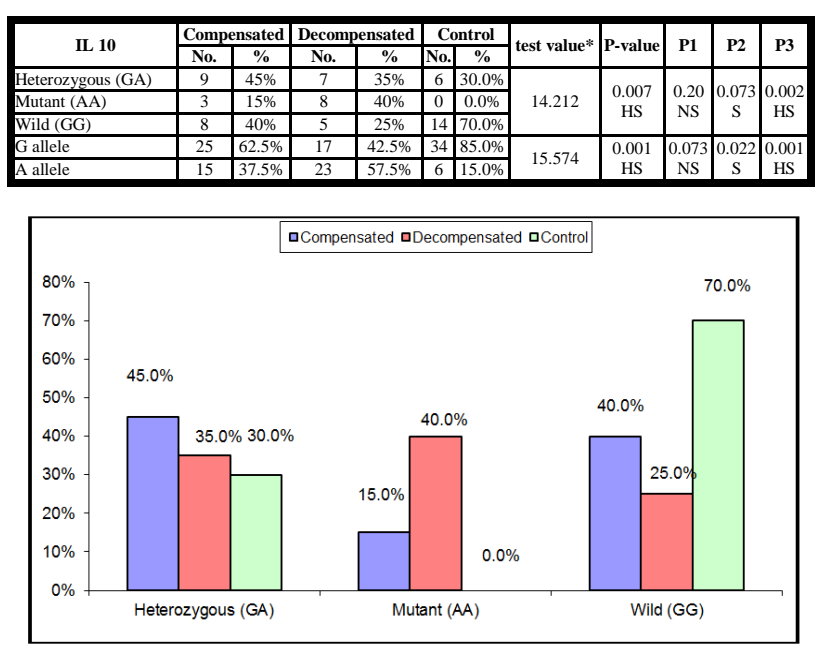

Fig. (5): IL10 genotypes in studied groups.

Table (6): Comparison of TGF $\beta 1$ polymorphism different allels among the studied groups.

\begin{tabular}{|c|c|c|c|c|c|c|c|c|c|c|c|}
\hline \multirow{2}{*}{ TGF beta 1} & \multicolumn{2}{|c|}{ Compensated } & \multicolumn{2}{|c|}{ Decompensated } & \multicolumn{2}{|c|}{ Control } & \multirow{2}{*}{ Test value* } & \multirow{2}{*}{ P-value } & \multirow[b]{2}{*}{ P1 } & \multirow{2}{*}{ P2 } & \multirow{2}{*}{ P3 } \\
\hline & No. & $\%$ & No. & $\%$ & No. & $\%$ & & & & & \\
\hline Heterozygous (CT) & 3 & $15 \%$ & 6 & $30 \%$ & 2 & $10.0 \%$ & \multirow{3}{*}{11.674} & \multirow{3}{*}{$0.020 \mathrm{~S}$} & \multirow{3}{*}{$0.176 \mathrm{NS}$} & \multirow{3}{*}{$0.017 \mathrm{~S}$} & \multirow{3}{*}{$0.117 \mathrm{NS}$} \\
\hline Mutant (CC) & 8 & $40 \%$ & 3 & $15 \%$ & 1 & $5.0 \%$ & & & & & \\
\hline Wild (TT) & 9 & $45 \%$ & 11 & $55 \%$ & 17 & $85.0 \%$ & & & & & \\
\hline $\mathrm{T}$ allele & 21 & $52.5 \%$ & 28 & $70.0 \%$ & 36 & $90.0 \%$ & \multirow{2}{*}{13.634} & \multirow{2}{*}{$0.001 \mathrm{HS}$} & \multirow{2}{*}{$0.108 \mathrm{NS}$} & \multirow{2}{*}{$0.001 \mathrm{HS}$} & \multirow{2}{*}{$0.025 \mathrm{~s}$} \\
\hline C allele & 19 & $47.5 \%$ & 12 & $30.0 \%$ & 4 & $10.0 \%$ & & & & & \\
\hline
\end{tabular}




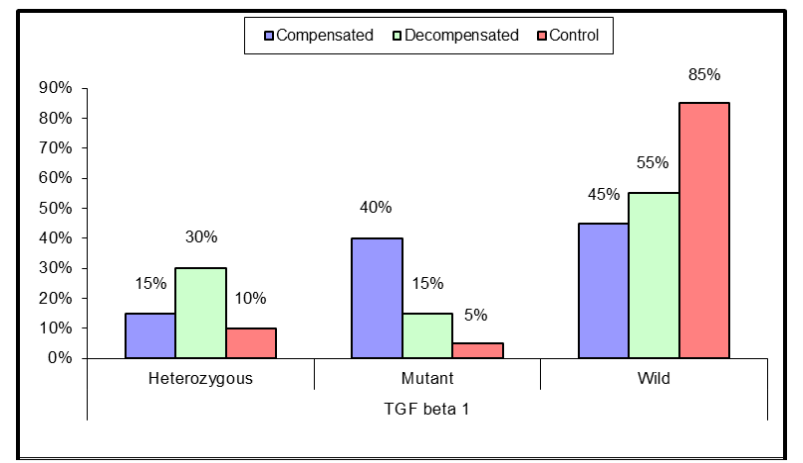

Fig. (6): TGF $\beta 1$ genotypes in studied groups.

\section{DISCUSSION}

Chronic hepatitis $\mathrm{C}$ is one of the major causes of liver fibrosis, with distortion of the hepatic architecture and ultimate progression to cirrhosis resulting in nodule formation. Approximately more than $3 \%$ of the total world population is chronically infected with $\mathrm{HCV}$ and due to gradual increase in the prevalence of $\mathrm{HCV}$; Chronic HCV is predicted to raise at least 3 folds by the year $2020^{(1)}$.

Clinical features of cirrhosis are derived from the morphologic alterations and often reflect the severity of the hepatic damage rather than the etiology of the underlying liver disease. Loss of functioning hepatocellular mass may lead to jaundice, edema, coagulopathy and a variety of metabolic abnormalities; finally leading to hepatocellular carcinoma (HCC) ${ }^{(\mathbf{1})}$.

The chronic liver disease patients suffer from multiple clinical conditions such as fever due to bacteraemia, abdominal pain due to colitis and organomegaly, loss of weight due to muscle catabolism, easy fatigability, nausea and vomiting due to gastritis and hyperbilirubinaemia, jaundice due to hyperbilirubinaemia, hematemesis and melena due to portal hypertension and lower limb edema due to hypo albuminaemia ${ }^{(9)}$.In our results these findings were highly significant in decompensated group compared to compensated group.

Regarding the ultrasonographic finding in chronic liver disease, the liver undergoes morphologic alteration as a result of hepatic damage which can be observed ultra sonography.Our results showed significant increase in portal vein diameter in de-compensated group versus compensated and control groups, left lobe of the liver was significantly shrunken in decompensated group versus control and compensated groups.Also there was significant increase in ascites in de-compensated group compared by compensated group ${ }^{(10)}$.

Hepatocyte injury results in altered cell membrane permeability causeing excessive leakage of transaminases which explain the highly significant increasein ALT and AST in both decompensated and compensated groups versus control group ${ }^{(10)}$.

Hyperbilirubinaemia is a sign of billiary obstruction or impaired hepatic function so the level of total bilirubin is an important finding in chronic liver disease. In our study, threre was high significant increase in bilirubin level in decompensated group as compared to both compensated and control groups ${ }^{(11)}$.

Serum albumin is exclusively synthsized by hepatocytes so albumin level less than $3.5 \mathrm{gm} / \mathrm{dl}$ should raise the suspision for cirrhosis. In our study there was highly significant decrease in albumin level in de-compensated group as compared to both ompensated and control groups ${ }^{\mathbf{1 1 1}}$.

Alfa-feto protein is a tumor marker used to identify hepatocellular carcinoma, serum level of $\alpha$-feto protein $>10 \mathrm{IU} / \mathrm{ml}$ suggest HCC.In our study we found significant increase in $\alpha$-feto protein level in de-compensated and compensated groups in comparison to control group. These results were consistent with those found by Saber et al. ${ }^{(12)}$ whom found $\alpha$-feto protein levelshowed significantly higher scores in malignant compared to peri-malignant hepatic tissue. The differences in AFP expression scores were also significant between different grades of the tumor. It was found that the number of cases positive for AFP was significantly increased in HCC compared to liver cirrhosis (LC).

IL-10 is an anti-inflammatory cytokine that plays an important role in the regulation of the immune response. The expression levels of this cytokine are associated with viral persistence due to the direct action of IL-10 on the mechanisms of innate and adaptive immunity ${ }^{(13)}$.

Variations in these levels have been directly related to the influence of IL-10 on the organization of the immune response and are associated with the presence of polymorphisms in the IL-10 gene. Most published studies 
demonstrate a relationship between chronic HCV infection and high levels of IL-10 production, confirming that some polymorphisms in the IL-10 gene promoter are crucial to determine the course of infection and eliminate the viral agent ${ }^{(13)}$.

Our study revealed that there was high significant increase in interleukin 10 polymorphism rs 1800896 in de-compensated group when compared to control group and the difference was significant in comparing compensated and control group. On the other hand there was no significant difference between compensated and decompensated groups when compared to each other.

Papatheodoridis et al. (14) study was reported that IL-10 gene polymorphism rs 1800896 was associated with the development of hepatocellular carcinoma, and could influence the long-term infection of chronic hepatitis B and C.

Liu et al. ${ }^{(15)}$ reported the association between IL-10 rs1800896, rs1800871 and rs1800872 polymorphisms and risk of liver cirrhosis, and they found that IL-10 rs1800896 polymorphism slightly enhanced the risk of liver cirrhosis.

Our results were consistent with Yaoet al. (16) who found that IL-10 rs1800896 polymorphism was associated with an increased risk of liver cirrhosis.

Regarding the allele frequency our study revealed that tha $\mathrm{A}$ alle is more frequent in decompensated cases (57.5\%), where $\mathrm{G}$ allele less frequent $(42.5 \%)$ which was inconsistent with the results found by Liu $\boldsymbol{e t} \boldsymbol{a l} .{ }^{(\mathbf{1 5})}$ whom found that the $\mathrm{G}$ allele is marginally increased in liver cirrhosis.

Our results were inconsistent with Nayle $\boldsymbol{e t}$ al. ${ }^{(17)}$ whom found that the genotype-1082 GG is more frequent in individuals infected with $\mathrm{HCV}$ than in healthy individuals. The genotype -1082 GG is responsible for high levels of IL-10 production, which then undermine the antiviral cellular immune response.

Transforming growth factor- $\beta$ (TGF- $\beta$ ) is a multifunctional cytokine involved in the regulation of growth and differentiation of a variety of normal cells and organs. It also plays an important role in the regulation of wound healing, angiogenesis, extracellular matrix formation, immunosuppression and cancer development ${ }^{(\mathbf{1 8})}$.
Changes in the production of TGF- $\beta$ have been linked to numerous disease states, including atherosclerosis and fibrous diseases of the kidney, liver and lung. In liver diseases, the persistence of chronic inflammation, as observed in chronic viral hepatitis, plays a major role in determining the shift in the TGF- $\beta$ signaling pathway from tumor suppression to fibro genesis accelerating liver fibrosis and increasing the risk of $\mathrm{HCC}^{(\mathbf{1 8 )}}$.

In our study there was significant increase in TGF- $\beta 1-509$ TT and CT genotypes in decompensated group than control group. These results were consistent with Mohy and Fouad ${ }^{(\mathbf{1 8})}$ whom found that TGFß1-509 CT and TT genotypes were significantly higher in cirrhotic group than control group.

Also these results were in agreement with the study done byFalleti et al. ${ }^{\left({ }^{9}\right)}$ which was conducted on $188 \mathrm{HCV}$ Italian patients and 140 healthy control. They found that CT and TT genotypes were significantly higher in cirrhotic group than control group.

In accordance with our study, an Egyptian study done byHanafy and Abdo ${ }^{(20)}$ found that the genotype and allele distribution of TGF- $\beta 1509$ CT SNPs; were significantly increased in chronic HCV patients compared to control group. Daiet al. (21) study which was conducted on Taiwanese HCV patients also showed similar results.

In Germany, Gewaltiget al. ${ }^{(22)}$ carried a study on the association of SNPs in the TGF- $\beta 1$ gene $-509 \mathrm{CT}$ and the rate of progression of HCVinduced fibrosis. They concluded that the homozygous TT genotype of -509 CT showed a slow progression of fibrosis.

Falletiet al. ${ }^{(19)}$ reported that the TGF- $\beta 1$ high producers of $-509 \mathrm{~T}$ genotype were found to be more represented in cirrhotic patients rather than in control subjects. These observations suggest a role of TGF- $\beta 1$ SNPs, present both in the promoter and in the coding regions, in causing accelerated liver fibrogenesis in patients with different types of liver disease, not only of viral origin.

The results of Liet al. ${ }^{(23)}$ were in contrast to ours and revealed that the frequency of TGF- $\beta 1$ -509 CC genotype was higher in liver cirrhosis (73.5\%) than control group (37.7\%); p b 0.05 .

Also other Chinese studies done byWanget al. ${ }^{(24)}$ were contradictory to the current results. 
They reported that the $\mathrm{C}$ allele at -509 may play an important role in the progression of liver cirrhosis than the $\mathrm{T}$ allele. Romani et al. ${ }^{(25)}$ found no significant difference in the allelic frequency distribution of SNPs at $-509 \mathrm{C} / \mathrm{T}$ between $\mathrm{HCV}$ patients and the healthy controls.

\section{CONCLUSION}

Interleukin 10 rs 1800896 gene polymorphism and TGF- $\beta 1509$ gene polymorphism are associated with risk of liver cirrhosis in patients with chronic hepatitis $\mathrm{C}$ virus infection. These findings could be useful for future studies for early detection of liver cirrhosis.

\section{REFERENCES}

1. Waqar A, Ijaz B, Gull S et al. (2011): Molecular, genetic and imaging techniques for HCV fibrosis evaluation, Virol. J., 8: 53-57.

2. Bruha R, Dvorak K, Petrtyl J (2012): Alcoholic liver disease. World Journal of Hepatology, 4(3):81.

3. Rockey DC and Bissell DM (2006): Noninvasive measures of liver fibrosis. Hepatology, 43(1):S113-120.

4. Sabat R, Grütz G, Warszawska K et al. (2010): Biology of interleukin-10.Cytokine Growth Factor Rev., 21(5):331-44.

5. Gigi E, Raptopoulou-Gigi $M$ and Kalogeridis A (2008): Cytokine mRNA expression in hepatitis $\mathrm{C}$ virus infection: $\mathrm{TH} 1$ predominance in patients with chronic hepatitis $\mathrm{C}$ and TH1-TH2 cytokine profile in subjects with self-limited disease. Journal of Viral Hepatitis, 15(2):145-154.

6. Othman MS, Aref AM, Mohamed AA et al. (2013): Serum levels of interleukin-6 and interleukin-10 as biomarkers for Hepatocellular carcinoma in Egyptian patients. ISRN Hepatology, 2013:412317.

7. Zekri AR, El-din Ashour MS, Hassan A et al. (2005): Cytokine profile in Egyptian hepatitis $\mathrm{C}$ virus genotype-4 in relation to liver disease progression. World Journal of Gastroenterology, 11(42):6624-6630.

8. Moustakas A and Heldin CH (2007): Signaling networks guiding epithelialmesenchymal transitions during embryogenesis and cancer progression. Cancer Sc., 98: 15121520 .
9. Anastácio LR, Ferreira LG, Ribeiro HD et al. (2012): Weight loss during cirrhosis is related to the etiology of liver disease. Arquivos de gastroenterologia, 49(3):195-8.

10. Contreras-Zentella ML and HernándezMuñoz R (2016): Is liver enzyme release really associated with cell necrosis induced by oxidant stress? Oxidative Medicine and Cellular Longevity, 2016: 218-233.

11. George Kasarala and Hans Tillman (2016): Standard liver tests. Clinical liver disease A Multimedia Review Journal, 8(1): 13-18.

12. Saber MA, AbdelHafiz S, Khorshed FE et al. (2017): Differential Expression of Glypican-3 and Insulin-Like Growth Factor-II mRNAs and Alpha-Fetoprotein and Ki-67 Markers in HCV Related Hepatocellular Carcinomas In Egyptian Patients. Asian, 18(1):121-127.

13. Swiatek BJ (2012): Is interleukin-10 gene polymorphism a predictive marker in $\mathrm{HCV}$ infection? Cytokine Growth Factor Rev., 23: 47-59.

14. Papatheodoridis GV, Chan HL, Hansen BE et al. (2015): Risk of hepatocellular carcinoma in chronic hepatitis B: assessment and modification with current antiviral therapy. Journal of hepatology, 62(4):956-67.

15. Liu Y, Yu MC, Zhang AQ et al. (2015): Interleukin-10 gene promoter polymorphism and risk of liver cirrhosis. Genet Mol Res., 14(1):1229-34.

16. Lanjie Y, Shuli X, Xueqin F et al. (2015): Association between interleukin-10 gene promoter polymorphisms and susceptibility to liver cirrhosis Int $\mathbf{J}$ Clin Exp Pathol., 8(9):11680-11684.

17. Naylê M, Silva $O$, NunesGermano $F$ et al. (2015): Polymorphisms of IL-10 gene in patients infected with $\mathrm{HCV}$ under antiviral treatment in southern Brazil.Cytokine, 6: 253257.

18. Mohy A and Fouad A (2014): Role of transforming growth factor- $\beta 1$ in serum and $509 \mathrm{C}>\mathrm{T}$ promoter gene polymorphism in development of liver cirrhosis in Egyptian patients.Meta Gene, 2: 631-637. 
19. Falleti E, Fabris $C$, Toniutto $P$ et al. (2008): TGF- $\beta 1$ genotypes in cirrhosis: relationship with the occurrence of liver cancer. Cytokine, 44: 256-261.

20. Hanafy SM and Abdo A (2011): Impact of single nucleotide polymorphism of TGF- $\beta 1$ gene (SNP-codon 10) on hepatocellular carcinoma risk in Egyptian patients following HCV infection. Aust. J. Basic Appl. Sci., 5 (9):1814-1821.

21. Dai CY, Chuang LP, Lee WC et al. (2008): Association between transforming growth factor-beta 1 polymorphism and virologic characteristics of chronic hepatitis C. Transl. Res., 152 (4):151-156.

22. Gewaltig J, Mangasser-Stephan K, Gartung C et al. (2002): Association of polymorphisms of the transforming growth factor-betal gene with the rate of progression of $\mathrm{HCV}$-induced liver fibrosis.Clin. Chim. Acta., 316:83-94.
23. Li H, Wu HL, Lv H et al. (2007): The association of TGF- $\beta 1$ and AT1R gene polymorphisms withhereditary susceptibility and clinical phenotype of $\mathrm{HBV}$-induced liver cirrhosis. Zhonghua Yi Xue Za Zhi, 24 (3):298-301.

24. Wang H, Zhao YP, Gao CF et al. (2008): Transforming growth factor-beta 1 gene variants increase transcription and are associated with liver cirrhosis in Chinese. Cytokine, 43 (1):20-25.

25. Romani S, Azimzadeh P, Mohebbi SR et al. (2011): Investigation of transforming growth factor-beta 1 gene polymorphisms among Iranian patients with chronic hepatitis C. Hepat., 11 (11):901-906. 